\title{
The dayside magnetopause location during radial interplanetary magnetic field periods: Cluster observation and model comparison
}

\author{
T. Huang ${ }^{1}$, H. Wang ${ }^{1,2}$, J.-H. Shue ${ }^{3}$, L. Cai ${ }^{1}$, and G. Pi ${ }^{3}$ \\ ${ }^{1}$ Dept. of Space Physics, School of Electronic Information, Wuhan University, Hubei, China \\ ${ }^{2}$ Sate Key Laboratory of Space Weather, Chinese Academy of Sciences, Beijing, China \\ ${ }^{3}$ Institute of Space Science, National Central University, Jhongli, Taiwan, Republic of China \\ Correspondence to: H. Wang (h.wang@whu.edu.cn)
}

Received: 19 July 2014 - Revised: 22 January 2015 - Accepted: 16 March 2015 - Published: 2 April 2015

\begin{abstract}
The present work has investigated the midlatitudinal magnetopause locations under radial interplanetary field (RIMF) conditions. Among 262 (256) earthward (sunward) RIMF events from years of 2001 to 2009, Cluster satellites have crossed the magnetopause 22(12) times, with 10 (7) events occurring at midlatitudes. The observed midlatitudinal magnetopause positions are compared with two empirical magnetopause models (Shue et al., 1998; Boardsen et al., 2000) (hereafter referred to as the Shue 98 model and the Boardsen00 model). The observation-model differences exhibit local time asymmetry. For earthward RIMF cases, the Shue98 model underestimates the magnetopause positions in the postnoon sector, while it overestimates the magnetopause positions in the dawn and dusk sectors. The Boardsen00 model generally underestimates the magnetopause after 6 MLT (magnetic local time), with larger deviations in the postnoon sector as compared to those in the prenoon. For sunward RIMF cases, the selected events are mainly clustered around the dawn and dusk sectors. The comparison with the Shue98 model indicates contractions in the dawn and expansions in the dusk sector, while the comparison with Boardsen00 indicates general expansions, with larger expansions in the later local time sectors. The local time variations in the differences between observations and the Shue9 98 and the Boardsen00 models indicate that the real magnetopause could be asymmetrically shaped during radial IMF periods, which should be considered by magnetopause models. The observation-model differences in the magnetopause positions $\left(\Delta R_{\mathrm{MP}}\right)$ during RIMF periods correlate well with the solar wind dynamic pressure, with larger $\Delta R_{\mathrm{MP}}$ for larger $P_{\mathrm{d}}$. The southern magnetopause expands further outward relative to the model prediction when the dipole tilt angle is
\end{abstract}

more negative (local summer in the Southern Hemisphere). For earthward RIMF cases, the generally good correlations between $\Delta R_{\mathrm{MP}}$ and the IMF cone angle are consistent with the previous hypothesis (Dušík et al., 2010) that, with more radial IMF, the subsolar magnetopause will expand further outward, owever, this is not the case for the comparison with Boardsen00 during sunward IMF periods, as it shows less dependence on the IMF cone angle.

Keywords. Magnetospheric physics (magnetopause cusp and boundary layers)

\section{Introduction}

The magnetopause is a thin boundary layer balanced by the total pressure in the magnetosheath and the magnetic pressure in the magnetosphere. The shape and structure of the magnetopause have been extensively studied in the past decades since the 1960s (refer to review paper by Eastwood et al. (2014)). The magnetopause location is dependent on the solar wind and interplanetary magnetic field (IMF) parameters (Aubry et al., 1971). The most important factors are IMF $B_{z}$ and solar wind dynamic pressure $\left(P_{\mathrm{dyn}}\right)$ (Shue et al., 2000; Fairfield, 2013). The magnetopause will move closer to the Earth under larger southward IMF and stronger dynamic pressure conditions (Shue et al., 2000). However, the movement of the magnetopause can cease for IMF $B_{z}<-20 \mathrm{nT}$, when saturation occurs. The critical value of IMF $B_{z}$ for saturation can increase with the increasing dynamic pressure (Yang et al., 2003). The saturation effect has been explained in terms of the enhanced region 1 field-aligned currents (FACs), the plasmaspheric effect or the enhanced ther- 
mal pressure in the magnetosphere and ring current during strong magnetic storms (Dmitriev and Suvorova, 2012). The influence of other parameters, such as the IMF $B_{y}$ component (Sibeck et al., 2000), Alfvénic fluctuations (Tsurutani et al., 2005) and solar wind discontinuities (e.g., Sibeck et al., 1999; Farrugia et al., 2008; Zhang et al., 2009; Jacobsen et al., 2009), on magnetopause locations has been examined in the literature, but it is not relevant to this work.

The dipole tilt angle of the Earth, the angle between the axis of the Earth-centered dipole moment and the $Z_{\mathrm{GSM}}$ axis, can also influence the shape of the magnetopause, which can cause hemispheric asymmetry (Shi et al., 2012). The shape of the dayside magnetopause in planes perpendicular to the Earth-Sun line is oblate, becoming blunt in the cusp regions (e.g., Petrinec and Russell, 1995; Sotirelis and Meng, 1999). The deepness and location of the indentation in the cusp regions are dependent on the dipole tilt angle (e.g., Šafránková et al., 2002; Lin et al., 2010; Boardsen et al., 2000). The magnetopause shows a dawn-dusk asymmetry during disturbed periods (i.e., $B_{z}<-6 \mathrm{nT}$ or $P_{\mathrm{dyn}}>20 \mathrm{nPa}$ ), and the magnetopause is located closer to the Earth on the dawnside than on the duskside (e.g., Kuznetsov and Suvorova, 1997, 1998; Dmitriev et al., 2004, 2011). The dawn-dusk asymmetry can be explained by the asymmetric ring current located in the premidnight sector (Dmitriev et al., 2004).

Some works have shown that the radial IMF (RIMF), when the IMF is directed along the solar wind velocity, may be another factor that can affect the magnetopause location. The magnetopause can expand outward during RIMF periods (e.g., Fairfield et al., 1990; Suvorova et al., 2010; Samsonov et al., 2012; Dušík et al., 2010). Suvorova et al. (2010) have reported that the magnetopause is outside its nominal dayside and nightside locations by using THEMIS (Time History of Events and Macroscale Interactions during Substorms) and Geotail observations. Merka et al. (2003) have found that the subsolar magnetopause is expanded by about 2 Earth radii $\left(R_{\mathrm{E}}\right)$ more than in Shue et al. (1998) model predictions (hereafter referred to as the Shue 98 model) by using crossing data from the spacecraft missions INTERBALL and IMP8 (Interplanetary Monitoring Platform). Dušík et al. (2010) have found that the difference in the magnetopause positions between the radial IMF and IMF perpendicular to the solar wind flow can statistically be about $1.7 R_{\mathrm{E}}$ different from THEMIS observations. The magnetopause oscillates for radial IMF orientations, with amplitudes varying from 0.2 to $2 R_{\mathrm{E}}$ (e.g., Sibeck and Newell, 1995; Russell et al., 1997; Laakso et al., 1998; Merka et al., 2003). The magnetopause can be distorted during radial IMF periods and become incurvate with an $1 R_{\mathrm{E}}$ deep and $2 R_{\mathrm{E}}$ wide indentation (Shue et al., 2009). These observations provide evidence that the subsolar magnetopause lies further away from the Earth for radial IMF orientations than indicated by model prediction.

Based on satellite observations, various empirical models of the magnetopause have been developed in the literature (e.g., Fairfield, 1971; Sibeck et al., 1991; Roelof and Sibeck,
1993; Petrinec and Russell, 1993, 1996; Kuznetsov and Suvorova, 1998; Shue et al., 1997; Boardsen et al., 2000; Chao et al., 2002; Lin et al., 2010; Lu et al., 2011). Most models have adopted the ellipsoid or quadratic equation or Shue model function for the magnetopause on the basis of lowlatitude magnetopause crossings parameterized by the solar dynamic pressure and/or the IMF $B_{z}$. The Shue 98 model has the flexibility to produce both an open and a closed magnetopause and can reasonably predict the distant tail (Shue et al., 1997). Boardsen et al. (2000) have constructed an empirical magnetopause model parameterized by solar wind dynamic pressure, IMF $B_{z}$ and dipole tilt angle, based on highlatitude magnetopause crossings from the Hawkeye observations and nose crossings from both Roelof and Sibeck (1993) and the Hawkeye spacecraft. Lu et al. (2011) have constructed a three-dimensional magnetopause model including the azimuthal asymmetry based on magnetohydrodynamics (MHD) model results, which can be applicable to both low and high latitudes for zero IMF $B_{x}, B_{y}$ and dipole tilt angle. The magnetopause models perform well during quiet and moderately disturbed conditions (Šafránková et al., 2002). The differences among these models increase with increasing disturbance levels (see the review paper by Shue et al. (2000)). For disturbed conditions the dayside magnetopause is more accurately predicted by models that have taken into account the saturation effect and dawn-dusk asymmetry (Dmitriev et al., 2004, 2011; Shue et al., 1998). The Shue98 model has been compared with other models during various solar wind conditions, and it turns out that it is among the best (Shue et al., 2000). However, the validations of the Shue98 model during radial IMF periods have not yet been confirmed statistically. The Boardsen model (Boardsen et al., 2000) (hereafter referred to as the Boardsen00 model), which takes into consideration the dipole tilt angle effect, is also used in the present work for comparison.

In the present work we will investigate the magnetopause locations during radial IMF conditions when IMF is parallel/antiparallel to the solar wind velocity. The investigations are based on Cluster observations when the spacecraft cross the magnetopause. The observed magnetopause locations have been compared with both the Shue 98 and the Boardsen00 model predictions. In the following section we describe the method of data processing. In Section 3 the cases studies are presented. In the Discussion section we compare the results with previous reports and offer explanations for the results.

\section{Data sets and models}

\subsection{Satellite data}

The ESA's Cluster spacecraft, with an orbital period of $57 \mathrm{~h}$, provides a good opportunity to investigate the magnetopause. The instruments of interest in the present study are flux- 
gate magnetometers (FGMs) for the vector magnetic field (Balogh et al., 2001) and ion spectrometer (CIS) for ion measurement (Rème et al., 2001). Similar to previous work (Hasegawa et al., 2004; Fuselier et al., 2012), we have identified magnetopause positions by using both plasma and magnetic field signatures. The magnetopause crossing is identified when two requirements are satisfied: (1) the magnetic field undergoes a transition from a steady geomagnetic-like field to a more highly fluctuating magnetosheath-like field; (2) ion number density has a sudden decrease from magnetosheath to magnetosphere or vice versa. For some cases when the identification is difficult, energy-time spectrograms are also used.

High-resolution (1 min) upstream solar wind data are normally from OMNI without special description and which have been time-propagated to the bow shock. The specific selection criterion for RIMF events is that the IMF cone angle, defined as the angle between the IMF and solar wind velocity, $\arccos \frac{B_{x}}{\sqrt{B_{x}{ }^{2}+B_{y}{ }^{2}+B_{z}^{2}}}$, is larger (smaller) than $145^{\circ}$ $\left(35^{\circ}\right)$; this criterion is looser than those in Pi et al. (2014). The RIMF period lasts for at least $2 \mathrm{~h}$, with small standard deviation of the angles $\left(\right.$ std $\left.<10^{\circ}\right)$. In total, 262 earthward and 256 sunward RIMF events have been picked out during the years 2001 to 2009. Among them, 22(12) crossings from Cluster are identified for earthward (sunward) RIMF cases.

\subsection{The Shue98 model}

Based on solar wind and IMF data from IMP-8 or ISEE (International Sun-Earth Explorer)-3 during magnetopause crossings observed by ISEE-1 \& 2 and IMP 8, Shue et al. (1997) have used the following function to describe the magnetopause shape:

$r=r_{0}\left(\frac{2}{1+\cos \theta}\right)^{\alpha}$

where $r$ is the radial distance, $\theta$ is the angle between $r$ and the Sun-Earth line direction, and $r_{0}$ and $\alpha$ represent the subsolar standoff distance and the level of tail flaring, respectively. For different tail flaring $(\alpha)$ the functional form has the flexibility to produce an open or a closed magnetopause and has a reasonable extrapolation ability to predict the distant tail magnetopause. Shue et al. (1998) have modified the dependence of $r_{0}$ and $\alpha$ on $B_{z}$ and $P_{\text {dyn }}$ to get an improved model (Shue et al., 1998). The newly derived model has the following relationship between $r_{0}, \alpha, B_{z}$ and $P_{\mathrm{dyn}}$ :

$$
\begin{aligned}
& r_{0}=\left[10.22+1.29 \times \tanh \left(0.184 \times\left(B_{z}+8.14\right)\right)\right] \\
& \times\left(P_{\text {dyn }}\right)^{-\frac{1}{6.6}} \alpha=\left(0.58-0.007 B_{z}\right) \\
& \times\left[1+0.024 \times \ln \left(P_{\text {dyn }}\right)\right] .
\end{aligned}
$$

\subsection{The Boardsen00 model}

Boardsen et al. (2000) magnetopause model is a secondorder surface function in a GSM coordinate system. By as- suming a symmetric plane about the GSM $x-z$ plane, the function contains no odd power terms in $y$, which is reduced to

$\boldsymbol{g}(\vec{p}, \vec{c})=c_{x x} x^{2}+c_{y y} y^{2}+c_{z z} z^{2}+c_{x z} x z$

$+c_{x} x+c_{z} z-1$,

where $\vec{p}$ is the magnetopause position and functions $\vec{c}$ are as follows:

$c_{x x}=\left[a_{x x 0}+a_{x x 2} \Psi_{R}^{2}+a_{x x 3} f_{3}\left(b_{z}\right)\right] s^{2}$

$c_{y y}=\left[a_{y y 0}+a_{y y 2} \Psi_{R}^{2}+a_{y y 3} f_{3}\left(b_{z}\right)\right] s^{2}$

$c_{z z}=\left[a_{z z 0}+a_{z z 2} \Psi_{R}^{2}+a_{z z 3} f_{3}\left(b_{z}\right)\right] s^{2}$

$c_{x z}=\left[a_{x z 1} \Psi_{R}\right] s^{2}$

$c_{x}=\left[a_{x 0}+a_{x 2} \Psi_{R}^{2}+a_{x 3} f_{3}\left(b_{z}\right)\right] s$

$c_{z}=\left(a_{z 1} \Psi_{R}\right) s$.

Here, the parameters $a_{x x 0}, a_{x x 2}, a_{x x 3}, a_{y y 0}, a_{y y 2}, a_{y y 3}, a_{z z 0}$, $a_{z z 2}, a_{z z 3}, a_{x z 1}, a_{x 0}, a_{x 2}, a_{x 3}$ and $a_{z 1}$ are the best-fit coefficients, given by Boardsen et al. (2000) for the cusp and nose region (see Tables 5a and 7 of Boardsen et al. (2000)). $s$ is the pressure scaling factor; $s=\left(p / p_{0}\right)^{\gamma}$, where $p$ is the solar wind dynamic pressure in units of $\mathrm{nPa}, p_{0}$ is set to a constant value of $3.0 \mathrm{nPa}$ and $\gamma$ is the power law coefficient. The $\Psi_{R}$ is defined as a function of dipole tilt angle $\Psi$, and $f_{3}\left(b_{z}\right)$ is the basis function for IMF $B_{z} ; \Psi_{R}$ is as follows:

$$
\begin{aligned}
& \Psi_{R}=\operatorname{frect}\left(\Psi,\left[t_{0}, t_{1}, t_{2}\right]\right) f_{3}\left(b_{z}, p\right) \\
& =-\operatorname{frect}\left(-b_{z},\left[p_{0}, p_{1}, p_{2}\right]\right),
\end{aligned}
$$

where $\left(t_{0}, t_{1}, t_{2}\right)$ and $\left(p_{0}, p_{1}, p_{2}\right)$ are rectification factors for the cusp region (see Tables $5 \mathrm{a}$ and 7 in Boardsen et al. (2000)). There are no rectification factors for the nose region $\left(\Psi_{R}=\Psi\right)$. "Frect" represents a rectification function, defined below, to rectify the discrepancy between observation and model fit:

$\operatorname{frect}(x, k)=k_{1} x+\left(1-k_{1}\right)\left[k_{0}+\left(x-k_{0}\right) h\left(x-k_{0}, k_{2}\right)\right]$

$h(x, a)=0.5[1+\tanh (a x)]$.

Here, $a, x,\left(k_{0}, k_{1}, k_{2}\right)$ are input parameters, $a$ controls the steepness of the step in $h(x, a)$, and $k_{0}$ controls where the transition in slope starts from a value of 1 to $k_{1}$.

\section{Observations}

\subsection{Case study}

First, we analyze one event on 19 May 2002, which covers a prolonged period of $10 \mathrm{~h}$ quasi-RIMF orientations. Figure 1 displays the diurnal variation in the solar wind and IMF parameters observed by the ACE (Advanced Composition Explorer) spacecraft; they have been time-shifted to the 
19 MAY 2002
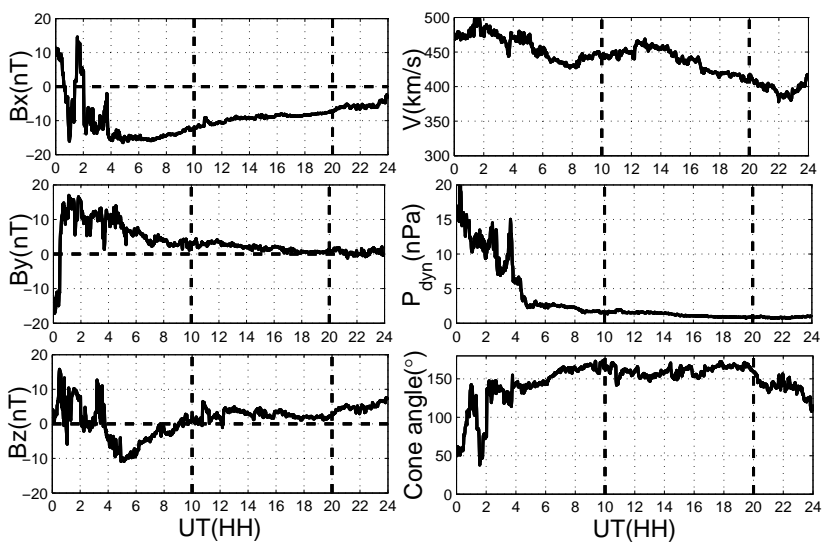

Figure 1. Temporal variations in solar wind and IMF parameters observed by the ACE satellite on 19 May 2002; these were timeshifted to the bow shock. The left panels show the IMF components $B_{x}, B_{y}, B_{z}$ in the GSM coordinate system, and the right panels show the solar wind speed $(\mathrm{V})$, dynamic pressure $\left(P_{\mathrm{dyn}}\right)$ and IMF cone angel, $\arccos \left(B_{x} / \sqrt{B_{x}^{2}+B_{y}^{2}+B_{z}^{2}}\right)$. The RIMF interval lasts for $10 \mathrm{~h}$ from 10:00 UT to 20:00 UT, as indicated by the vertical dashed line.

bow shock by using the actual solar wind speed data (the propagation has been done by the standard procedure described on the web page:http://omniweb.gsfc.nasa.gov/html/ ow_data.html\#time_shift). Figure 1 contains three components of IMF $B_{x}, B_{y}, B_{z}$ in the GSM coordinate system: solar wind velocity $(V)$, dynamic pressure $\left(P_{\mathrm{dyn}}\right)$ and the IMF cone angle. IMF $B_{z}$ reaches its minimum around 4.5 UT and turns northward after 10:00 UT, with an average value of $2.5 \mathrm{nT}$. After 10:00 UT, $B_{y}$ has an average magnitude of $1.8 \mathrm{nT}$, and the earthward $B_{x}$ has an average value of $-9.2 \mathrm{nT}$. It is apparent that the IMF $B_{x}$ component is dominant from 10:00 to 20:00 UT, which has been indicated by the vertical dashed line. During the RIMF period, $P_{\text {dyn }}$ stays around $1.2 \mathrm{nPa}$ and the IMF cone angle remains around $160^{\circ}$. $\mathrm{AE}$ (auroral electrojet) index is on average about $100 \mathrm{nT}$ during RIMF. $D_{\mathrm{ST}}$ has a long recovery from a previous weak storm with an average value of about $-40 \mathrm{nT}$. Both indices indicate a weak geomagnetic condition (AE and $D_{\mathrm{ST}}$ plots are not shown in Fig. 1).

During the RIMF period, Cluster spacecraft have crossed the dawnside magnetopause in the low-latitudinal flank region from the magnetosphere into the magnetosheath. Figure 2 shows the temporal variation in the magnetic field ( $B_{x}, B_{y}$ and $B_{z}$ in the GSM coordinate system), ion density and energy-time spectrograms for the differential energy flux of electrons in the parallel and antiparallel directions from 10:00 UT to 24:00 UT as observed by the Cluster 3 (C3) spacecraft. The $10 \mathrm{eV}$ in the two bottom panels indicates the level of the spacecraft potential, as measured by the EFW (Electric Field and Wave Experiment) instrument

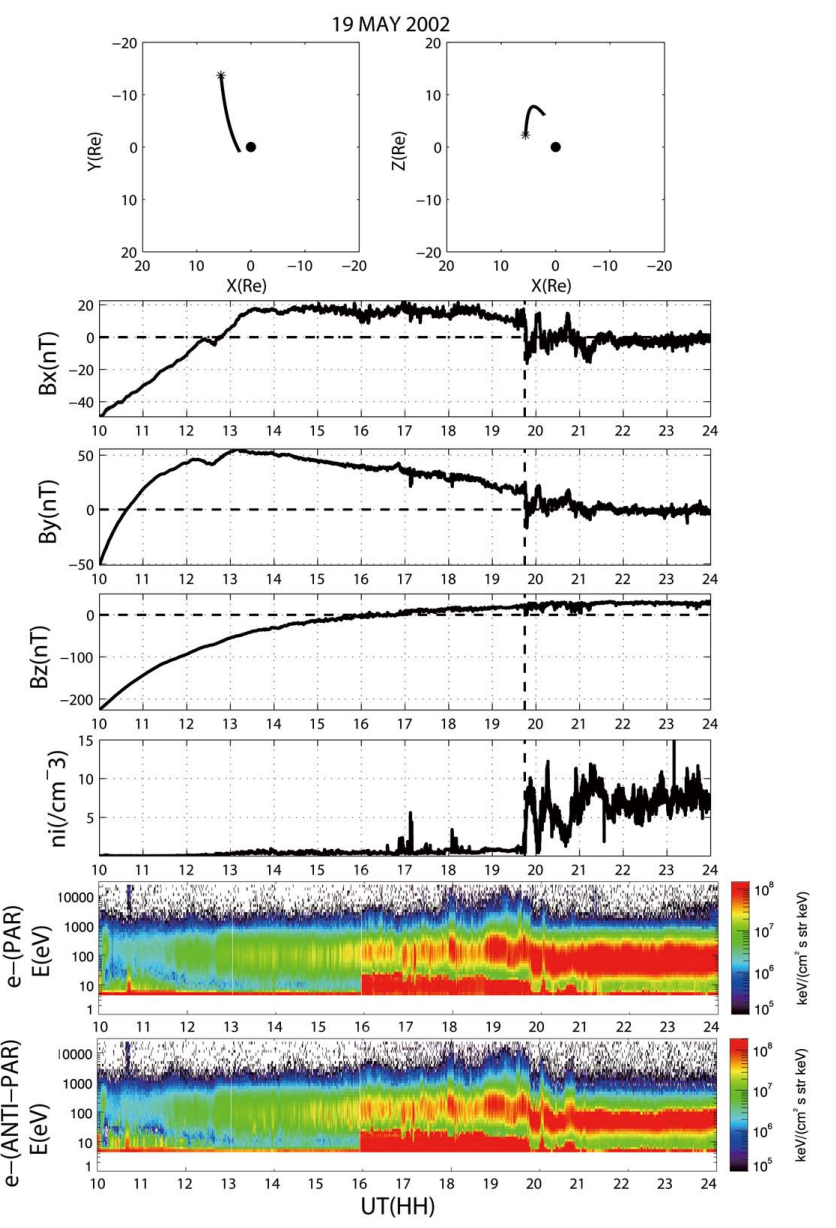

Figure 2. The temporal variation in the plasma and magnetic field observations by Cluster 3 (C3) during the RIMF period on 19 May 2002. From top to bottom, the figure shows the magnetic field components $B_{x}, B_{y}, B_{z}$ in the GSM coordinate system, the ion number density $\left(n_{i}\right)$, and electron fluxes parallel and antiparallel to the magnetic field from 10:00 UT to 24:00 UT. The orbital track of C3 in the GSM coordinate system is also shown in the top panel.

on C3. The observation of electrons with energies lower than the spacecraft potential is due to the photoelectron population originating with the spacecraft and should be disregarded (Bogdanova et al., 2006). The magnetopause crossing occurs at a low latitude, with the latitude (defined as the co-angle away from the GSM $z$ axis; $\operatorname{Lat}_{G S M}=\arctan \left(z / \sqrt{x^{2}+y^{2}}\right)$ ) being about $10^{\circ}$ in the Northern Hemisphere, and the magnetic local time is about 7.1 MLT. The magnetic field components change from a geomagnetic field-like structure before 19:45:00 UT to a magnetosheath field after 19:45:00 UT. Coincident with the magnetic field changes, there is a significant enhancement of the number density from 1 to about $10 \mathrm{~cm}^{-3}$, which is a characteristic value in the magnetosheath. An apparent change is also observed in the electron distribution: the high-energy population $(1 \mathrm{keV}<E<20 \mathrm{keV})$ disappears and low-energy electrons $(30 \mathrm{eV}<E<600 \mathrm{eV})$ be- 
come more evident. High fluxes of suprathermal electrons are observed in the magnetosheath after 19:45:00 UT. All these features indicate a magnetopause crossing from the magnetosphere into the magnetosheath. The magnetopause crossing always involves multiple crossings because the slow spacecraft speed is around $2.5 \mathrm{~km} \mathrm{~s}^{-1}$ around 19:45:00 UT, while the boundary motions can range from less than $5 \mathrm{~km} \mathrm{~s}^{-1}$ to more than $50 \mathrm{~km} \mathrm{~s}^{-1}$ (Fairfield, 1971). Therefore, one can see in Fig. 2 that the magnetic field components and ion density fluctuate several times between 19 and 20:00 UT. For simplicity, we have treated them as a single crossing event. The location of the satellite for the first crossing at 19:45:00 UT is selected as the location of the magnetopause. At 19:45:00 UT, C3 is at $\left[X_{\mathrm{GSM}}=5.5 R_{\mathrm{E}}, Y_{\mathrm{GSM}}=-13.5 R_{\mathrm{E}}\right.$, $\left.Z_{\mathrm{GSM}}=2.6 R_{\mathrm{E}}\right]$ in the GSM coordinate system.

The magnetopause shape predicted by the Shue 98 model at 19:45:00 UT is shown in GSM coordinate systems in Fig. 3, with averaged IMF $B_{x}=-8.1 \mathrm{nT}, B_{y}=1.34 \mathrm{nT}$, $B_{z}=2.0 \mathrm{nT}$, cone angle $=162.9^{\circ}$ and $P_{\text {dyn }}=0.94 \mathrm{nPa}$. The solar wind parameters are $10 \mathrm{~min}$ averaged values preceding the magnetopause crossing time. The orbital track of $\mathrm{C} 3$ during the radial IMF period is also shown, with a red dot indicating the $\mathrm{C} 3$ position at the time of magnetopause crossing at 19:45:00 UT. It can be seen that the observed magnetopause is located further outside of the modeled magnetopause, with the radial difference $\left(\Delta R_{\mathrm{MP}}=R_{\mathrm{obs}}-R_{\mathrm{mod}}\right)$ being $0.45 R_{\mathrm{E}}$. This means that Cluster observes the magnetopause at a distance of $0.45 R_{\mathrm{E}}$ further away from the Earth than the Shue98 model predicts it to be. For the C1,C2 and $\mathrm{C} 4$ spacecrafts, the radial differences between the observation and model are $0.45 R_{\mathrm{E}}, 0.45 R_{\mathrm{E}}$ and $0.46 R_{\mathrm{E}}$ around 19:45:00 UT, respectively. Since the satellites are located quite close to each other and we are focusing on large-scale structures, in the following study we only use the $\mathrm{C} 3$ observations. The difference between the observation and the Boardsen00 magnetopause model can be calculated to be about $0.94 R_{\mathrm{E}}$ for the C3 satellite.

\subsection{Multi-events study}

During all RIMF events from 2001 to 2009, Cluster spacecraft crossed the magnetopause (3-21 MLT) 22 (12) times under earthward (sunward) IMF conditions. The observation-model differences in the magnetopause locations $\left(\Delta R_{\mathrm{MP}}\right)$ have been calculated for each crossing event. The corresponding crossing time and location $(x, y, z$ in GSM coordinate system, latitude and MLT) of the C3 spacecraft, the averaged solar wind and IMF parameters (IMF $B_{x}$, $B_{y}, B_{z}$, solar wind velocity, dynamic pressure, IMF cone angle), and dipole tilt angle are listed in Tables 1 and 2 for earthward and sunward RIMF events. Under earthward (sunward) conditions, there are 10 (7) midlatitudinal crossing events (i.e., $30^{\circ}<$ Lat $_{\mathrm{GSM}}<60^{\circ}$ ), 7(3) low-latitudinal crossing events (i.e., $\mathrm{Lat}_{\mathrm{GSM}} \leq 30^{\circ}$ ) and $5(2)$ high-latitudinal crossing (i.e., Lat $_{\mathrm{GSM}} \geq 60^{\circ}$ ) events. The 10 and 7 midlati- tudinal crossings under earthward and sunward RIMF conditions are marked with asterisks in Tables 1 and 2; they are the focus of the present study.

Figure 4 shows the distribution of $\Delta R_{\mathrm{MP}}$ as a function of MLT. The left panel is for the comparison with the Shue 98 and the right panel is for the comparison with the Boardsen00 model. From top to bottom, earthward and sunward RIMF events are shown. Blue dots are for the southern hemispheric crossings and red dots are for the northern hemispheric crossings. A positive value of $\Delta R_{\mathrm{MP}}$ means that the observed magnetopause lies outside of the model prediction, and vice versa. For the earthward RIMF events, the correlation of $\Delta R_{\mathrm{MP}}$ with MLT is good for the Boardsen00 model (correlation coefficient $r=0.8$ ), while the correlation is poor for the Shue 98 model. However, the local time asymmetry in the observation-model differences can be seen for both the Shue 98 and the Boardsen00 models. The Shue98 model underestimates the magnetopause positions in the postnoon sector (12-17 MLT), while it overestimates the magnetopause positions in the dawn (5-8 MLT) and dusk (18-21 MLT) sectors. When compared to the Boardsen00 model, the observed magnetopause generally expands after 6 MLT, with a larger expansion in the postnoon sector than in the prenoon sector. As for the sunward RIMF crossing events, the correlation between the observation and model differences is also better for the Boardsen00 model compared to the Shue 98 model. The comparison with Shue98 during sunward RIMF periods indicates that the magnetopause contracts before 19 MLT, while it expands after 19MLT; the comparison with Boardsen00 shows general expansions, with a larger expansion in the later local times, except for one case in the Northern Hemisphere.

\section{Discussion}

The analysis of magnetopause locations observed by Cluster spacecraft during radial IMF periods was carried out in the present work. The observed magnetopause positions have been compared with those predicted by the Shue 98 and the Boardsen00 magnetopause models. The deviations of observations from the Shue98 (Boardsen00) model in our statistical study are within the range of $-2-4.1 R_{E}$, as shown in Fig. 4. Dušík et al. (2010) have found that the average deviation from the magnetopause model in the subsolar region for nearly radial IMF conditions is, on average, $1.7 R_{\mathrm{E}}$. Merka et al. (2003) have found that the magnetopause position is $2 R_{\mathrm{E}}$ more distant than in the Shue98 model prediction. Suvorova et al. (2010) have reported that the expansion is global and that the magnetopause is located more than $3 R_{\mathrm{E}}$ and $7 R_{\mathrm{E}}$ outside its nominal dayside and magnetotail locations. Results from Merka et al. (2003) and Suvorova et al. (2010) were based on event studies, while those from Dušík et al. (2010) were based on statistical studies. In Dušík et al. (2010) (Fig. 4), one can see that the range of the observation 


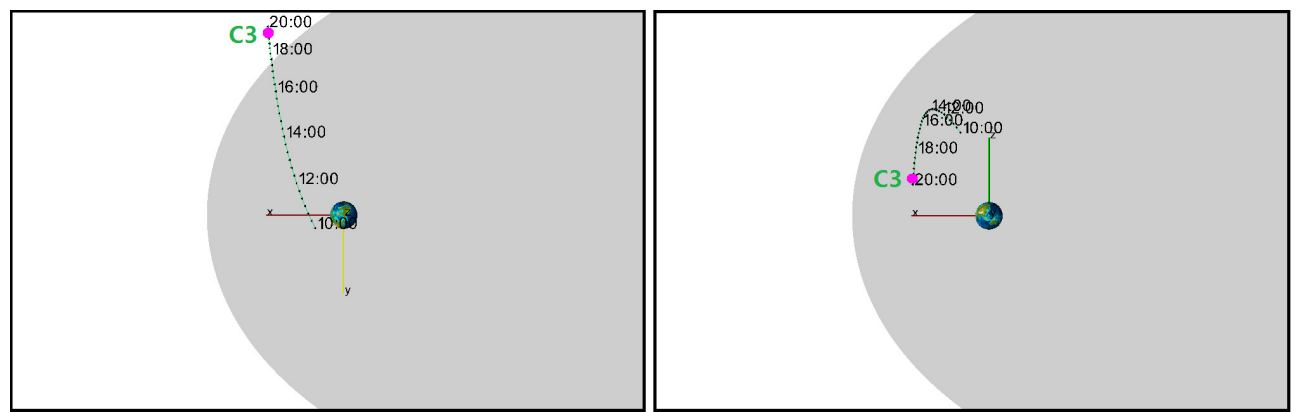

Figure 3. Orbital tracks of Cluster 3 in the framework of the Shue98 magnetopause model in the GSM coordinate system from 10 to 20:00 UT on 19 May 2002. Two views in both $x-y$ and $x-z$ planes are shown to clarify the location of C3 relative to the magnetopause. The opaque planes depict the magnetopause from the Shue98 model at 19:45 UT, and C3 is located outside the predicted magnetopause, as indicated by the red dot.

Table 1. The corresponding parameters for magnetopause crossings during earthward RIMF (IMF $B_{x}<0$ ). Event date, time (UT), Cluster position in the GSM coordinate system, latitude, magnetic local time (MLT), difference between the observed and modeled magnetopause position, corresponding solar wind and IMF parameters, IMF $B_{x}, B_{y}, B_{z}$, solar wind velocity $(V)$, dynamic pressure $\left(P_{\text {dyn }}\right)$, IMF cone angle, and dipole tilt angle are given from left to right. The midlatitude crossings are marked with asterisks.

\begin{tabular}{|c|c|c|c|c|c|c|c|c|c|c|c|c|c|}
\hline EVENTS & $\begin{array}{r}\text { UT } \\
\text { (hour) }\end{array}$ & $\begin{array}{r}X_{\mathrm{GSM}} \\
\left(R_{\mathrm{E}}\right)\end{array}$ & $\begin{array}{r}Y_{\mathrm{GSM}} \\
\left(R_{\mathrm{E}}\right)\end{array}$ & $\begin{array}{r}Z_{\mathrm{GSM}} \\
\left(R_{\mathrm{E}}\right)\end{array}$ & $\mathrm{Lat}_{\mathrm{GSM}}$ & $\begin{array}{r}\text { MLT } \\
\text { (hour) }\end{array}$ & $\begin{array}{r}B_{x} \\
(\mathrm{nT})\end{array}$ & $\begin{array}{r}B_{y} \\
(\mathrm{nT})\end{array}$ & $\begin{array}{r}B_{z} \\
(\mathrm{nT})\end{array}$ & $\begin{array}{r}V \\
\left(\mathrm{~m} \mathrm{~s}^{-1}\right)\end{array}$ & $\begin{array}{l}P_{\text {dyn }} \\
(\mathrm{nPa})\end{array}$ & $\begin{array}{r}\text { Cone } \\
\text { angle }\left({ }^{\circ}\right)\end{array}$ & $\begin{array}{r}\text { Dipole } \\
\text { tilt angle }\left({ }^{\circ}\right)\end{array}$ \\
\hline 31 Jan 2001* & 6.14 & 6.8 & 5.7 & 10.6 & 50.1 & 13.8 & -5.1 & 0.2 & -2.0 & 366 & 2.3 & 157.9 & -27.2 \\
\hline 16 Jan $2002 *$ & 1.08 & 4.9 & 6.1 & 11.2 & 54.9 & 14.2 & -5.3 & -0.1 & -1.3 & 387 & 1.6 & 165.8 & -26.0 \\
\hline 21 Dec $2002 *$ & 10.89 & 6.2 & 5.7 & -11.0 & -52.5 & 14.2 & -7.5 & -1.62 & 0.8 & 463 & 4.2 & 166.2 & -22.8 \\
\hline 18 Feb $2003 *$ & 23.04 & 7.5 & 3.1 & -9.5 & -49.5 & 14.2 & -6.2 & -0.3 & 2.5 & 585 & 2.1 & 157.4 & -11.2 \\
\hline $19 \mathrm{Feb} 2003$ & 13.76 & 3.5 & 2.0 & 7.7 & 62.5 & 13.7 & -6.2 & -0.9 & -0.7 & 510 & 2.63 & 169.8 & -4.4 \\
\hline $22 \mathrm{Feb} 2005$ & 12.78 & 3.2 & -1.4 & -9.7 & -70.3 & 9.8 & -4.5 & 0.1 & -0.5 & 395 & 1.7 & 172.6 & -5.5 \\
\hline 1 Apr 2005 & 13.30 & 1.5 & -2.7 & -10.8 & -74.1 & 9.3 & -3.9 & 1.9 & 1.6 & 406 & 3.3 & 147.1 & 10.6 \\
\hline 26 Apr 2005 & 2.096 & 9.7 & -9.3 & 0.1 & 0.4 & 9.1 & -3.9 & -0.3 & 1.4 & 454 & 1.0 & 160.6 & 5.9 \\
\hline 16 May $2005 *$ & 10.65 & -0.2 & -11.5 & -11.5 & -44.9 & 7.0 & -7.9 & -2.7 & -1.2 & 625 & 1.3 & 159.8 & 18.6 \\
\hline 24 May 2005 & 17.94 & 4.6 & -14.8 & -1.4 & -5.0 & 7.1 & -6.0 & 1.1 & 0.1 & 390 & 0.8 & 169.9 & 30.3 \\
\hline 22 Jun $2006 *$ & 23.52 & -7.8 & -12.6 & -12.5 & -40.2 & 5.2 & -4.1 & -0.7 & 1.6 & 330 & 2.0 & 156.6 & 21.4 \\
\hline 9 May 2008 & 12.41 & 8.7 & -9.5 & -1.3 & -5.7 & 8.7 & -3.8 & -0.1 & 0.5 & 424 & 1.1 & 171.9 & 21.4 \\
\hline 26 May 2008 & 5.43 & 5.7 & -12.6 & -3.0 & -12.5 & 7.9 & -2.8 & -0.1 & -1.0 & 412 & 0.7 & 160.6 & 11.5 \\
\hline 1 July 2008 & 3.74 & -5.4 & -16.9 & -4.5 & -14.3 & 5.2 & -3.8 & -1.4 & -1.0 & 444 & 1.4 & 155.7 & 13.7 \\
\hline 17 May $2009 *$ & 4.76 & -1.0 & -9.6 & -12.9 & -53.2 & 6.6 & -2.5 & 1.2 & -0.0 & 356 & 0.9 & 156.7 & 9.6 \\
\hline
\end{tabular}

and model differences is also within $-2 R_{\mathrm{E}}$ and $4 R_{\mathrm{E}}$, which is consistent with our results.

Our work has shown that the observation-model differences exhibit local time variations, which are dependent on the model used for comparison in the analysis. For earthward RIMF cases, the Shue98 model underestimates the magnetopause positions in the postnoon sector, while it overestimates the magnetopause positions in the dawn and dusk sectors. These results might be consistent with the idea of the bullet-shaped magnetopause in Merka et al. (2003) while inclining more to the postnoon sector, i.e., the subsolar magnetopause around noon is larger than the model prediction, while the flank magnetopause in the dawn and dusk sectors is less than the model prediction. When compared to the Boardsen00 model, the observed magnetopause generally expands after 6 MLT. This might support the global expansion of the dayside magnetopause by Suvorova et al. (2010). Furthermore, our result also indicates that the global expansion is not distributed homogenously according to local time. Larger expansion occurs in the postnoon sector compared to that in the prenoon sector. For sunward RIMF cases, the events are mainly clustered around the dawn and dusk sectors. The comparison with the Shue98 model indicates contractions (three events) in the dawn and expansions (two out 
Table 2. Same as Table 1 but for the sunward RIMF periods (IMF $B_{x}>0$ ).

\begin{tabular}{|c|c|c|c|c|c|c|c|c|c|c|c|c|c|}
\hline EVENTS & $\begin{array}{r}\mathrm{UT} \\
\text { (hour) }\end{array}$ & $\begin{array}{r}X_{\mathrm{GSM}} \\
\left(R_{\mathrm{E}}\right)\end{array}$ & $\begin{array}{r}Y_{\mathrm{GSM}} \\
\left(R_{\mathrm{E}}\right)\end{array}$ & $\begin{array}{r}Z_{\mathrm{GSM}} \\
\left(R_{\mathrm{E}}\right)\end{array}$ & Lat $_{\mathrm{GSM}}$ & $\begin{array}{r}\text { MLT } \\
\text { (hour) }\end{array}$ & $\begin{array}{r}B_{x} \\
(\mathrm{nT})\end{array}$ & $\begin{array}{r}B_{y} \\
(\mathrm{nT})\end{array}$ & $\begin{array}{r}B_{z} \\
(\mathrm{nT})\end{array}$ & $\begin{array}{r}V \\
\left(\mathrm{~m} \mathrm{~s}^{-1}\right)\end{array}$ & $\begin{array}{l}P_{\text {dyn }} \\
(\mathrm{nPa})\end{array}$ & $\begin{array}{r}\text { Cone } \\
\text { angle }\left({ }^{\circ}\right)\end{array}$ & $\begin{array}{r}\text { Dipole } \\
\text { tilt angle }\left({ }^{\circ}\right)\end{array}$ \\
\hline 12 Jan $2003 *$ & 16.95 & 5.0 & 8.8 & 8.2 & 39.1 & 15.6 & 8.4 & 0.9 & -2.9 & 368.2 & 0.8 & 19.7 & -11.3 \\
\hline $25 \operatorname{Dec} 2003 *$ & 6.40 & 5.9 & 4.3 & -10.5 & -55.3 & 18.9 & 4.3 & -0.4 & 0.7 & 392.8 & 0.9 & 10.8 & -32.7 \\
\hline 21 Apr 2006 & 1.90 & 9.2 & -6.6 & 1.1 & 5.8 & 9.6 & 4.6 & 1.4 & -0.1 & 388.0 & 2.0 & 16.4 & 4.5 \\
\hline 16 May 2006* & 6.70 & -1.1 & -9.3 & -13.6 & -55.5 & 6.4 & 2.3 & -0.3 & 0.2 & 356.8 & 0.9 & 8.2 & 10.4 \\
\hline 16 May $2006 *$ & 7.33 & 0.4 & 8.2 & -15.4 & -55.3 & 6.3 & 2.4 & 0.5 & 0.5 & 351.9 & 1.0 & 16.9 & 11.2 \\
\hline 17 Nov 2008 & 7.88 & -1.3 & -9.2 & -13.3 & -62.0 & 20.5 & 3.5 & 0.0 & 1.2 & 409.4 & 1.0 & 18.5 & -25.3 \\
\hline 26 Dec 2008 & 14.03 & -2.5 & 13.7 & -13.1 & -19.3 & 18.0 & 3.0 & -0.3 & 1.1 & 391.0 & 1.1 & 20.5 & -15.9 \\
\hline 14 Apr 2009 & 3.42 & -8.0 & -16.0 & -11.6 & -66.1 & 7.8 & 3.1 & -0.3 & -0.6 & 362.9 & 0.7 & 12.9 & 0.3 \\
\hline 26 Jun $2009 *$ & 3.75 & -6.1 & 14.8 & -12.8 & -32.9 & 5.1 & 3.3 & 1.2 & -0.4 & 450.7 & 1.2 & 20.9 & 14.0 \\
\hline
\end{tabular}
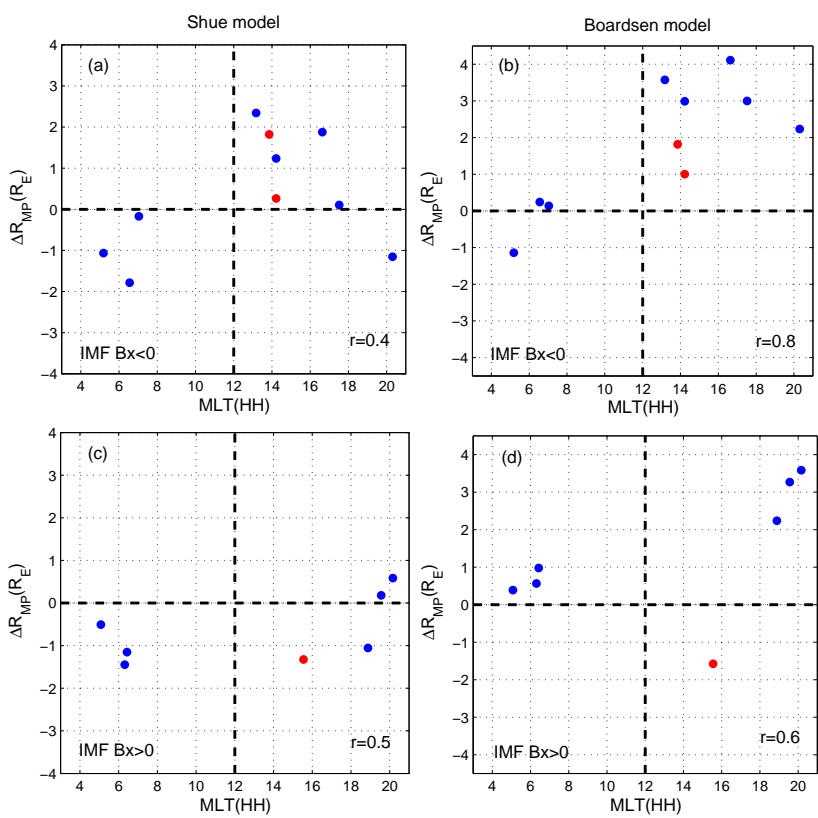

Figure 4. The MLT variation in the differences in the magnetopause locations at midlatitudes $\left(\Delta R_{\mathrm{MP}}\right)$ observed by Cluster and predicted by the Shue 98 model (left panels) and the Boardsen 00 model (right panels). From top to bottom, the figure shows earthward and sunward IMF events. A positive value means that the observed magnetopause is located further outward than the model prediction, and negative values mean the opposite. Red (blue) colors indicate northern (southern) crossings. The correlation coefficients are given.

of three events) in the dusk sector, while the comparison with Boardsen00 indicates general expansions, with larger expansions in the later local time sectors. The local time variations in the differences between observations and the Shue 98 or the Boardsen00 models indicate that the real magnetopause could be asymmetrically shaped during radial IMF periods, which should be considered by magnetopause models.

Samsonov et al. (2012) have proposed a theoretical explanation of the sunward expansion of the subsolar magne- topause with a radial IMF by using both statistical THEMIS observations and model simulations. There are two processes that can lead to a decrease in the total pressure in the magnetosheath during a radial IMF period and that cause the expansion of the magnetopause. Due to the solar wind entering the magnetosheath through the bow shock, the dynamic pressure decreases and the thermal pressure increases. The diversion of the plasma along the magnetopause can result in reduced thermal pressure during a radial IMF period. On the other hand, the magnetic pressure is negligibly small due to the disappearance of the magnetic barrier for a radial IMF case according to numerical calculations. Therefore, the total pressure on the magnetopause turns out to be $20 \%$ lower than the solar wind dynamic pressure (Samsonov et al., 2013). In addition, the oscillation of the magnetopause caused by the unsteady-state character of transition processes can account for the larger displacement of the magnetopause, which can exceed the distance between two equilibrium positions when IMF is perpendicular or parallel to the solar wind velocity (Samsonov et al., 2013).

According to previous work the main factors that control the magnetopause locations are IMF $B_{z}$, dipole tilt angle and solar wind dynamic pressure $\left(P_{\text {dyn }}\right)$. Thus, it might be reasonable to examine the model performance with respect to these parameters. During the RIMF periods in the present work, both IMF $B_{z}$ and $B_{y}$ components are relatively small $\left(-3.6 \mathrm{nT}<B_{y}<2.9 \mathrm{nT},-2.8 \mathrm{nT}<B_{z}<3.1 \mathrm{nT}\right)$; thus, the relationship between IMF $B_{y}$ and $B_{z}$ are not obvious (figures in question not shown here). The observation-model differences seem not to be explained by IMF $B_{y}$ or $B_{z}$ components.

The differences between observations and models are shown in Fig. 5 as functions of $P_{\text {dyn }}$. For the Shue98 model, $\Delta R_{\mathrm{MP}}$ shows good correlations with the dynamic pressure, with the correlation coefficient being $0.8(0.7)$ for earthward (sunward) IMF cases. With larger dynamic pressure, the magnetopause seems to be located further outside of the model prediction. For the Boardsen00 model, the correlation coefficient between $\Delta R_{\mathrm{MP}}$ and the dynamic pressure is 0.5 , 

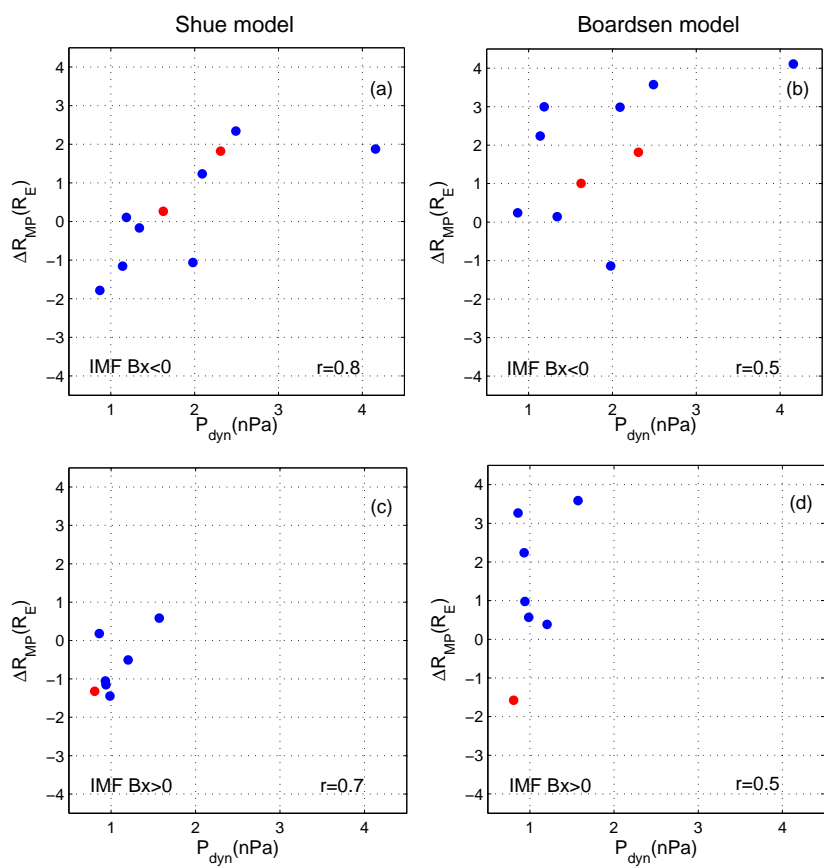

Figure 5. Differences between observed and modeled magnetopause as a function of the dynamic pressure. Panels from top to bottom show earthward and sunward IMF crossing events. Left (right) panels are the results of the Shue98 (Boardsen00) model. The correlation coefficients are given. Red (blue) dots indicate the northern (southern) midlatitudinal crossings.

not as good as that of the Shue98 model. However, the tendency with the dynamic pressure is similar, i.e., the magnetopause is located further outward with larger dynamic pressure. Both the Shue 98 and the Boardsen00 models are scaled by the solar wind dynamic pressure and IMF $B_{z}$ component thus, $\Delta R_{\mathrm{MP}}$ can be regarded as a residual, with the dynamic pressure effect excluded. The pressure on the magnetopause is $k * P_{d}$, where $P_{\mathrm{d}}$ is the solar wind dynamic pressure and $k$ the conversion factor. The variable value of $k$ is used to denote the fraction of the dynamic pressure that is exerted on the magnetopause, depending upon IMF $B_{z}$ (Shue and Chao., 2013); this is much lower for radial IMF (Suvorova et al., 2010). However, the magnetopause models commonly assume a constant $k$ for all solar wind conditions, say, $k=k_{1}$. We also assume that $k$ is equal to $k_{0}$ (smaller than $k_{1}$ ) for radial IMF. Thus, the magnetopause difference between the observation and model $\Delta R_{\mathrm{MP}}$ is proportional to $\left(\left(k_{1}-k_{0}\right) * P_{\mathrm{d}}\right)^{(-1 / 6)}$, with a larger $\Delta R_{\mathrm{MP}}$ for a larger $P_{\mathrm{d}}$.

Figure 6 shows the observation-model differences as a function of the dipole tilt angle during earthward and sunward IMF periods. The correlation is calculated for both northern (red dot) and southern (blue dots) midlatitudinal crossings. It is obvious that the analysis is weighted towards the Southern Hemisphere because of only two events occurring in the Northern Hemisphere. One can find an apparent asymmetry in the negative and positive dipole tilt angles
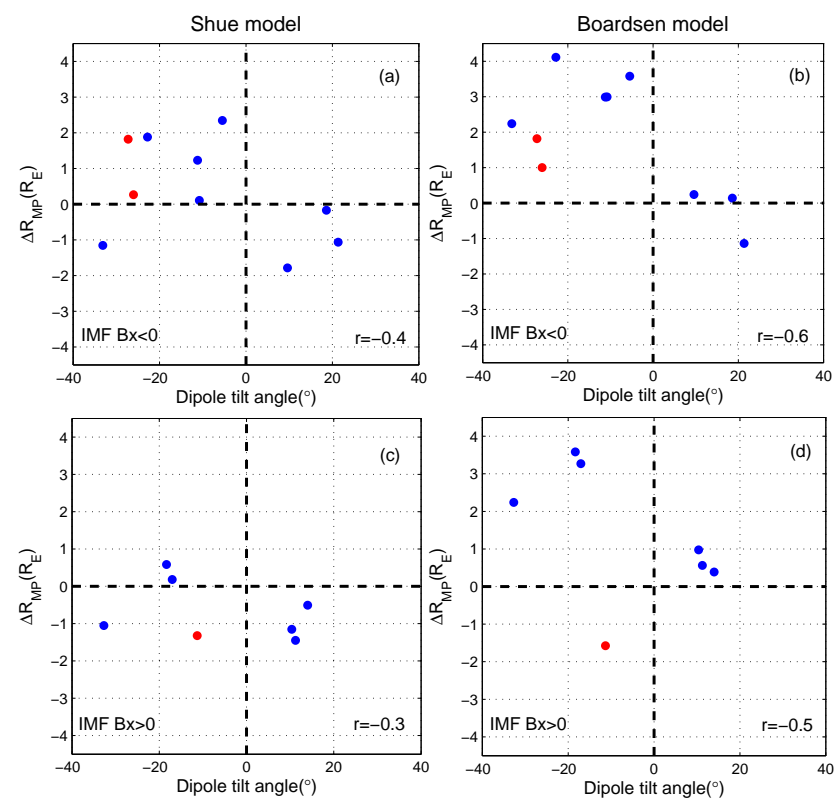

Figure 6. Same as Fig. 5 but for the dipole tilt angle.

for both earthward and sunward RIMF events. The magnetopause expands further outward relative to the model prediction when the dipole tilt angle is more negative (local summer in the Southern Hemisphere). Note that the dipole tilt angle is not included in the Shue98 model, while it is included in the Boardsen00 model. The latter fact indicates that the dipole tilt effect is not fully represented by the Boardsen00 model. Previous work has shown that the dipole tilt angle has few effects on the equatorial magnetopause but has great effects on the high-latitude magnetopause (Lin et al., 2010; Liu et al., 2012; Boardsen et al., 2000). As the dipole tilt angle becomes more negative, the high-latitude magnetopause is displaced inwards in the Northern Hemisphere, while in the Southern Hemisphere the magnetopause is displaced outward (Boardsen et al., 2000). This is consistent with our results in midlatitudes. The correlation between $\Delta R_{\mathrm{MP}}$ and the dipole tilt angle is not good except in the Boardsen00 model during earthward RIMF periods. As discussed above, the incomplete removal effects of the dynamic pressure might partly account for the marginal correlation between $\Delta R_{\mathrm{MP}}$ and the dipole tilt angle.

The model performance as a function of the IMF cone angle is shown in Fig. 7. The left panel shows the results in comparison with the Shue98 and the right in comparison with the Boardsen00 model. For earthward RIMF cases (top), the generally good correlations between $\Delta R_{\mathrm{MP}}$ and the IMF cone angle ( $r=0.5$ for the Shue98 and 0.6 for the Boardsen00 model) are consistent with the previous hypothesis (Dušík et al., 2010) that, with more radial IMF, the subsolar magnetopause will expand further outward. For sunward RIMF events (bottom), the comparison with the Shue98 model is consistent with the results in Dušík et al. (2010), 

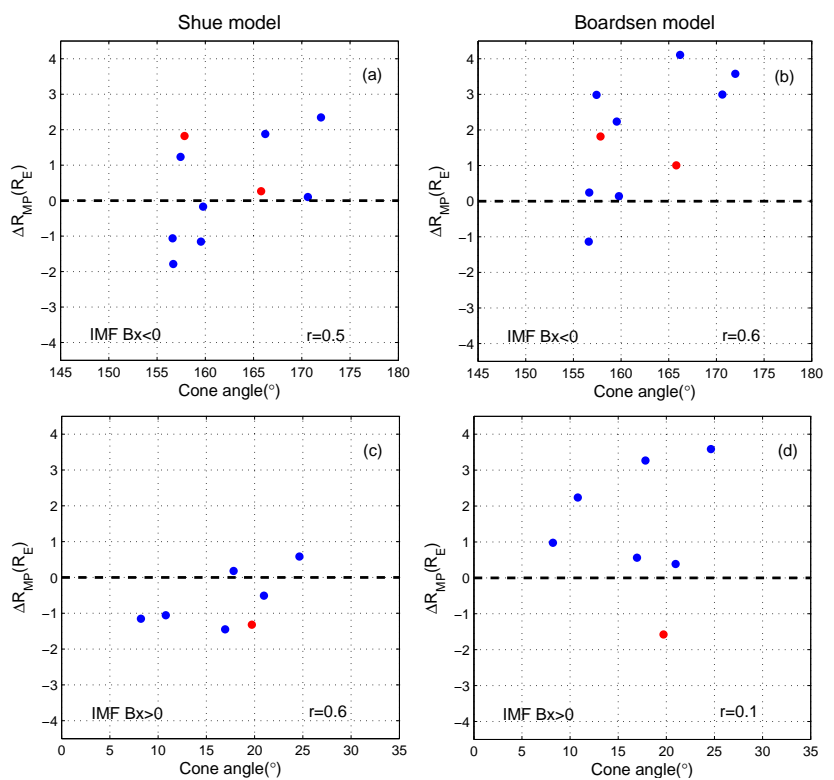

Figure 7. Same as Fig. 5 but for the IMF cone angle.

while the comparison with Boardsen00 shows less dependence on the IMF cone angle. As we have discussed above, the radial IMF can further reduce the total pressure in the magnetosheath, thus causing the magnetopause expansion (Samsonov et al., 2013). The ignorance of the IMF cone angle can cause significant deviations of model predictions from observations. Previous work has shown that the solar wind dynamic pressure can affect the magnetopause size, while the shape of the magnetopause is controlled by the IMF $B_{z}$ (e.g., Shue et al., 1997; Lu et al., 2011; Boardsen et al., 2000). Later work has further indicated that the dipole tilt angle can also affect the magnetopause shape (e.g., Liu et al., 2012). Our work has indicated that the IMF cone angle might be another important parameter that can affect the magnetopause shape. We should say that our results are based on relatively small numbers of midlatitudinal crossings. Future work with multi-spacecraft observations of the magnetopause are needed to verify our view of the magnetopause positions for radial IMF periods.

\section{Summary}

We have compared magnetopause positions in the range of 3 to 21 MLT as identified by Cluster satellites with two empirical models - Shue98 (Shue et al., 1997) and Boardsen00 (Boardsen et al., 2000) - under radial interplanetary magnetic field (RIMF) conditions. From the years 2001 to 2009, Cluster satellites have crossed the magnetopause 22 (12) times, with 10 (7) events occurring in midlatitudes during earthward (sunward) RIMF periods. The differences between observed and modeled magnetopause positions $\left(\Delta R_{\mathrm{MP}}\right)$ show local time variations. For earthward RIMF cases, the Shue 98 model underestimates the magnetopause positions in the postnoon sector (six events), while it overestimates the magnetopause positions in the dawn (three events) and dusk sectors (one event). When compared to the Boardsen00 model, the observed magnetopause generally expands after 6 MLT, with a larger expansion occurring in the postnoon sector compared to the prenoon sector (nine events). For sunward RIMF cases, the selected events are mainly clustered around dawn (three events) and dusk sectors (three events). The comparison with the Shue98 model indicates contractions (three events) in the dawn and expansions (two out of three events) in the dusk sector, while the comparison with Boardsen00 indicates general expansions, with larger expansions in the later local time sectors. The local time variations in the differences between observations and the Shue98 and the Boardsen00 models indicate that the real magnetopause could be asymmetrically shaped during radial IMF periods, which should be considered by magnetopause models. The differences between observed and modeled magnetopause positions $\left(\Delta R_{\mathrm{MP}}\right)$ shows dependencies on the dynamic pressure for both models. With larger dynamic pressure, the observed magnetopause seems to be located further outside of the model prediction. The dependence of $\Delta R_{\mathrm{MP}}$ on the solar wind dynamic pressure indicates that both models do not fully represent the dynamic pressure effects. The southern magnetopause expands further outward relative to the model prediction when the dipole tilt angle is more negative (local summer in the Southern Hemisphere). For earthward RIMF cases, the generally good correlations between $\Delta R_{\mathrm{MP}}$ and the IMF cone angle are consistent with the previous hypothesis (Dušík et al., 2010) that, with more radial IMF, the subsolar magnetopause will expand further outward. However, this is not the case for the comparison with Boardsen00 during sunward IMF periods, as it shows less dependence on the IMF cone angle.

Future work with multi-spacecraft observations of the magnetopause in combination with model simulations are needed to verify the above results of the magnetopause positions during radial IMF periods. 
Acknowledgements. The Cluster and ACE teams and NASA/GSFC's Space Physics Data Facility's OMNIWeb service are gratefully acknowledged for satellite operation and data processing. This work is supported by the National Nature Science Foundation of China (nos. 41222030, 41221003 and 41431073), the Program for Young Excellent Scientist by the Organization Department, Program for New Century Excellent Talent in University by the Ministry of Education. The work of J.-H. Shue and G. Pi was partially supported by grant MOST-103-2111-M-008-020 to National Central University.

Topical Editor E. Roussos thanks C. Xiong and two anonymous referees for their help in evaluating this paper.

\section{References}

Aubry, M. P., Kivelson, M. G., and Russell, C. T.: Motion and structure of the magnetopause, J. Geophys. Res., 76, 1673-1696, doi:10.1029/JA076i007p01673, 1971.

Balogh, A., Carr, C. M., Acuña, M. H., Dunlop, M. W., Beek, T. J., Brown, P., Fornacon, K.-H., Georgescu, E., Glassmeier, K.H., Harris, J., Musmann, G., Oddy, T., and Schwingenschuh, K.: The Cluster Magnetic Field Investigation: overview of in-flight performance and initial results, Ann. Geophys., 19, 1207-1217, doi:10.5194/angeo-19-1207-2001, 2001.

Boardsen, S. A., Eastman, T. E., Sotirelis, T., and Green, J. L.: An empirical model of the high-latitude magnetopause, J. Geophys. Res., 105, 23193-23219, doi:10.1029/1998JA000143, 2000.

Bogdanova, Y. V., Owen, C. J., Fazakerley, A. N., Klecker, B., and Réme, H.: Statistical study of the location and size of the electron edge of the Low-Latitude Boundary Layer as observed by Cluster at mid-altitudes, Ann. Geophys., 24, 2645-2665, doi:10.5194/angeo-24-2645-2006, 2006.

Chao, J., Wu, D., Lin, C.-H., Yang, Y.-H., Wang, X., Kessel, M., Chen, S., and Lepping, R.: Models for the size and shape of the earth's magnetopause and bow shock, in: Space Weather Study Using Multipoint Techniques Proceedings of the COSPAR Colloquium, edited by: Lyu, L.-H., Vol. 12 of COSPAR Colloquia Series, 127-135, Pergamon, doi:10.1016/S09642749(02)80212-8, 2002.

Dmitriev, A. V., Suvorova, A. V., Chao, J. K., and Yang, Y.-H.: Dawn-dusk asymmetry of geosynchronous magnetopause crossings, J. Geophys. Res., 109, A05203, doi:10.1029/2003JA010171, 2004.

Dmitriev, A., Suvorova, A., and Chao, J.-K.: A predictive model of geosynchronous magnetopause crossings, J. Geophys. Res., 116, A05208, doi:10.1029/2010JA016208, 2011.

Dmitriev, A. and Suvorova, A.: Equatorial trench at the magnetopause under saturation, J. Geophys. Res., 117, A08226, doi:10.1029/2012JA017834, 2012.

Dušík, v., Granko, G., Šafránková, J., Němeček, Z., and Jelínek, K.: IMF cone angle control of the magnetopause location: Statistical study, Geophys. Res. Lett., 37, L19103, doi:10.1029/2010GL044965, 2010.

Eastwood, J., Hietala, H., Toth, G., Phan, T., and Fujimoto, M.: What Controls the Structure and Dynamics of Earth's Magnetosphere?, Space Sci. Rev., doi:10.1007/s11214-014-0050-x, 2014.
Fairfield, D. H.: Average and unusual locations of the Earth's magnetopause and bow shock, J. Geophys. Res., 76, 6700-6716, doi:10.1029/JA076i028p06700, 1971.

Fairfield, D. H., Baumjohann, W., Paschmann, G., Lühr, H., and Sibeck, D. G.: Upstream pressure variations associated with the bow shock and their effects on the magnetosphere, J. Geophys. Res., 95, 3773-3786, doi:10.1029/JA095iA04p03773, 1990.

Fairfield, D. H.: Observations of the Shape and Location of the Magnetopause: A Review, 53-60, Am. Geophys. Union, doi:10.1029/GM090p0053, 2013.

Farrugia, C. J., Gratton, F. T., Lund, E. J., Sandholt, P. E., Cowley, S. W. H., Torbert, R. B., Gnavi, G., Mann, I. R., Bilbao, L., Mouikis, C., Kistler, L., Smith, C. W., Singer, H. J., and Watermann, J. F.: Two-stage oscillatory response of the magnetopause to a tangential discontinuity/vortex sheet followed by northward IMF: Cluster observations, J. Geophys. Res., 113, A03208, doi:10.1029/2007JA012800, 2008.

Fuselier, S. A., Trattner, K. J., Petrinec, S. M., and Lavraud, B.: Dayside magnetic topology at the Earth's magnetopause for northward IMF, J. Geophys. Res., 117, A03208, doi:10.1029/2012JA017852, 2012.

Hasegawa, H., Sonnerup, B. U. Ö., Dunlop, M. W., Balogh, A., Haaland, S. E., Klecker, B., Paschmann, G., Lavraud, B., Dandouras, I., and Réme, H.: Reconstruction of two-dimensional magnetopause structures from Cluster observations: verification of method, Ann. Geophys., 22, 1251-1266, doi:10.5194/angeo22-1251-2004, 2004.

Jacobsen, K. S., Phan, T. D., Eastwood, J. P., Sibeck, D. G., Moen, J. I., Angelopoulos, V., McFadden, J. P., Engebretson, M. J., Provan, G., Larson, D., and Fornaçon, K.-H.: THEMIS observations of extreme magnetopause motion caused by a hot flow anomaly, J. Geophys. Res., 114, doi:10.1029/2008JA013873, 2009.

Kawano, H., Petrinec, S. M., Russell, C. T., and Higuchi, T.: Magnetopause shape determinations from measured position and estimated flaring angle, J. Geophys. Res., 104, 247-261, doi:10.1029/98JA02479, 1999.

Kuznetsov, S. N. and Suvorova, A. V.: Magnetopause shape near geosynchronous orbit, Geomagnetizm i Aehronomiya, 3, 1-11, 1997.

Kuznetsov, S. N. and Suvorova, A. V.: An Empirical Model of the Magnetopause for Broad Ranges of Solar Wind Pressure and $B_{Z}$ IMF, in Polar Cap Boundary Phenomena, edited by: Moen, J., Egeland, A. and Lockwood, M. TS2, 51-61, Kluwer Acad., Norwell, Mass, doi:10.1007/978-94-011-5214-3-5, 1998.

Laakso, H., Fairfield, D. H., Collier, M. R., Opgenoorth, H., Phan, T.-D., Sibeck, D. G., Giles, B. L., Singer, H. J., Lepping, R. P., Lin, R. P., Mozer, F. S., Pfaff, R. F., Tsuruda, K., and Wygant, J. R.: Oscillations of magnetospheric boundaries driven by IMF rotations, Geophys. Res. Lett., 25, 3007-3010, doi:10.1029/98GL50916, 1998.

Lin, R. L., Zhang, X. X., Liu, S. Q., Wang, Y. L., and Gong, J. C.: A three-dimensional asymmetric magnetopause model, J. Geophys. Res., 115, A04207, doi:10.1029/2009JA014235, 2010.

Liu, Z.-Q., Lu, J. Y., Kabin, K., Yang, Y. F., Zhao, M. X., and Cao, X.: Dipole tilt control of the magnetopause for southward IMF from global magnetohydrodynamic simulations, J. Geophys. Res., 117, A07207, doi:10.1029/2011JA017441, 2012. 
Lu, J. Y., Liu, Z.-Q., Kabin, K., Zhao, M. X., Liu, D. D., Zhou, Q., and Xiao, Y.: Three dimensional shape of the magnetopause: Global MHD results, J. Geophys. Res., 116, A09237, doi:10.1029/2010JA016418, 2011.

Merka, J., Szabo, A., Šafránková, J., and Němeček, Z.: Earth's bow shock and magnetopause in the case of a field-aligned upstream flow: Observation and model comparison, J. Geophys. Res., 108, 1269, doi:10.1029/2002JA009697, 2003.

Petrinec, S. M. and Russell, C. T.: An empirical model of the size and shape of the near-Earth magnetotail, Geophys. Res. Lett., 20, 2695-2698, doi:10.1029/93GL02847, 1993.

Petrinec, S. M. and Russell, C. T.: Comments on "Magnetopause shape as a bivariate function of interplanetary magnetic field $\mathrm{Bz}$ and solar wind dynamic pressure" by E. C. Roelof and D. G. Sibeck, J. Geophys. Res., 100, 1899-1901, doi:10.1029/94JA02627, 1995.

Petrinec, S. M. and Russell, C. T.: Near-Earth magnetotail shape and size as determined from the magnetopause flaring angle, J. Geophys. Res., 101, 137-152, doi:10.1029/95JA02834, 1996.

Pi, G., Shue, J.-H., Chao, J. K., Němeček, Z., Šafránková, J., and Lin, C.-H.: A reexamination of long-duration radial IMF events, J. Geophys. Res., 119, 7005-7011, doi:10.1002/2014JA019993, 2014.

Rème, H., Aoustin, C., Bosqued, J. M., Dandouras, I., Lavraud, B., Sauvaud, J. A., Barthe, A., Bouyssou, J., Camus, T., Coeur-Joly, O., Cros, A., Cuvilo, J., Ducay, F., Garbarowitz, Y., Medale, J. L., Penou, E., Perrier, H., Romefort, D., Rouzaud, J., Vallat, C., Alcaydé, D., Jacquey, C., Mazelle, C., d'Uston, C., Möbius, E., Kistler, L. M., Crocker, K., Granoff, M., Mouikis, C., Popecki, M., Vosbury, M., Klecker, B., Hovestadt, D., Kucharek, H., Kuenneth, E., Paschmann, G., Scholer, M., Sckopke, N., Seidenschwang, E., Carlson, C. W., Curtis, D. W., Ingraham, C., Lin, R. P., McFadden, J. P., Parks, G. K., Phan, T., Formisano, V., Amata, E., Bavassano-Cattaneo, M. B., Baldetti, P., Bruno, R., Chionchio, G., Di Lellis, A., Marcucci, M. F., Pallocchia, G., Korth, A., Daly, P. W., Graeve, B., Rosenbauer, H., Vasyliunas, V., McCarthy, M., Wilber, M., Eliasson, L., Lundin, R., Olsen, S., Shelley, E. G., Fuselier, S., Ghielmetti, A. G., Lennartsson, W., Escoubet, C. P., Balsiger, H., Friedel, R., Cao, J.-B., Kovrazhkin, R. A., Papamastorakis, I., Pellat, R., Scudder, J., and Sonnerup, B.: First multispacecraft ion measurements in and near the Earth's magnetosphere with the identical Cluster ion spectrometry (CIS) experiment, Ann. Geophys., 19, 1303-1354, doi:10.5194/angeo-19-1303-2001, 2001.

Roelof, E. C. and Sibeck, D. G.: Magnetopause shape as a bivariate function of interplanetary magnetic field $\mathrm{Bz}$ and solar wind dynamic pressure, J. Geophys. Res., 98, 21421-21450, doi:10.1029/93JA02362, 1993.

Russell, C. T., Petrinec, S. M., Zhang, T. L., Song, P., and Kawano, H.: The effect of foreshock on the motion of the dayside magnetopause, Geophys. Res. Lett., 24, 1439-1441, doi:10.1029/97GL01408, 1997.

Šafránková, J., Němeček, Z., Dušík, v., Přech, L., Sibeck, D. G., and Borodkova, N. N.: The magnetopause shape and location: a comparison of the Interball and Geotail observations with models, Ann. Geophys., 20, 301-309, doi:10.5194/angeo-20-301-2002, 2002.

Samsonov, A. A., Němeček, Z., Šafránková, J., and Jelínek, K.: Why does the subsolar magnetopause move sunward for radial interplanetary magnetic field?, J. Geophys. Res., 117, A05221, doi:10.1029/2011JA017429, 2012.

Samsonov, A., Němeček, Z., Šafránková, J., and Jelínek, K.: Why does the total pressure on the subsolar magnetopause differ from the solar wind dynamic pressure?, Cosmic Res., 51, 37-45, doi:10.1134/S0010952513010073, 2013.

Shi, J., Guo, J., Dunlop, M., Zhang, T., Liu, Z., Lucek, E., Fazakerley, A., Rème, H., and Dandouras, I.: Inter-hemispheric asymmetry of dependence of the cusp location on dipole tilt during northward IMF conditions, Ann. Geophys., 30, 21-26, doi:10.5194/angeo-30-21-2012, 2012.

Shue, J.-H., Chao, J. K., Fu, H. C., Russell, C. T., Song, P., Khurana, K. K., and Singer, H. J.: A new functional form to study the solar wind control of the magnetopause size and shape, J. Geophys. Res., 102, 9497-9511, doi:10.1029/97JA00196, 1997.

Shue, J.-H., Song, P., Russell, C. T., Steinberg, J. T., Chao, J. K., Zastenker, G., Vaisberg, O. L., Kokubun, S., Singer, H. J., Detman, T. R., and Kawano, H.: Magnetopause location under extreme solar wind conditions, J. Geophys. Res., 103, 17691-17700, doi:10.1029/98JA01103, 1998.

Shue, J.-H., Song, P., Russell, C. T., Chao, J. K., and Yang, Y.-H.: Toward predicting the position of the magnetopause within geosynchronous orbit, J. Geophys. Res., 105, 2641-2656, doi:10.1029/1999JA900467, 2000.

Shue, J.-H., Chao, J.-K., Song, P., McFadden, J. P., Suvorova, A., Angelopoulos, V., Glassmeier, K. H., and Plaschke, F.: Anomalous magnetosheath flows and distorted subsolar magnetopause for radial interplanetary magnetic fields, Geophys. Res. Lett., 36, L18112, doi:10.1029/2009GL039842, 2009.

Shue, J.-H., and J.-K. Chao.: The role of enhanced thermal pressure in the earthward motion of the Earth's magnetopause, J. Geophys. Res., 118, 3017-3026, doi:10.1002/jgra.50290, 2013.

Sibeck, D. G., Lopez, R. E., and Roelof, E. C.: Solar wind control of the magnetopause shape, location, and motion, J. Geophys. Res., 96, 5489-5495, doi:10.1029/90JA02464, 1991.

Sibeck, D. G. and Newell, P. T.: Pressure-pulse driven surface waves at the magnetopause: A rebuttal, J. Geophys. Res., 100, 21773 21778, doi:10.1029/95JA01635, 1995.

Sibeck, D. G., Borodkova, N. L., Schwartz, S. J., Owen, C. J., Kessel, R., Kokubun, S., Lepping, R. P., Lin, R., Liou, K., Lühr, H., McEntire, R. W., Meng, C.-I., Mukai, T., Nemecek, Z., Parks, G., Phan, T. D., Romanov, S. A., Safrankova, J., Sauvaud, J.-A., Singer, H. J., Solovyev, S. I., Szabo, A., Takahashi, K., Williams, D. J., Yumoto, K., and Zastenker, G. N.: Comprehensive study of the magnetospheric response to a hot flow anomaly, J. Geophys. Res., 104, 4577-4593, doi:10.1029/1998JA900021, 1999.

Sibeck, D. G., Kudela, K., Lepping, R. P., Lin, R., Nemecek, Z., Nozdrachev, M. N., Phan, T.-D., Prech, L., Safrankova, J., Singer, H., and Yermolaev, Y.: Magnetopause motion driven by interplanetary magnetic field variations, J. Geophys. Res., 105, 25155-25169, doi:10.1029/2000JA900109, 2000.

Sotirelis, T. and Meng, C.-I.: Magnetopause from pressure balance, J. Geophys. Res., 104, 6889-6898, doi:10.1029/1998JA900119, 1999.

Suvorova, A. V., Shue, J.-H., Dmitriev, A. V., Sibeck, D. G., McFadden, J. P., Hasegawa, H., Ackerson, K., Jelínek, K., Šafránková, J., and Němeček, Z.: Magnetopause expansions for quasi-radial interplanetary magnetic field: THEMIS 
and Geotail observations, J. Geophys. Res., 115, A10216, doi:10.1029/2010JA015404, 2010.

Tsurutani, B. T., Lakhina, G. S., Pickett, J. S., Guarnieri, F. L., Lin, N., and Goldstein, B. E.: Nonlinear Alfvén waves, discontinuities, proton perpendicular acceleration, and magnetic holes/decreases in interplanetary space and the magnetosphere: intermediate shocks?, Nonlinear Proc. Geophys., 12, 321-336, doi:10.5194/npg-12-321-2005, 2005.
Yang, Y.-H., Chao, J. K., Dmitriev, A. V., Lin, C.-H., and Ober, D. M.: Saturation of IMF Bz influence on the position of dayside magnetopause, J. Geophys. Res., 108, 1104, doi:10.1029/2002JA009621, 2003.

Zhang, H., Zong, Q.-G., Sibeck, D. G., Fritz, T. A., McFadden, J. P., Glassmeier, K.-H., and Larson, D.: Dynamic motion of the bow shock and the magnetopause observed by THEMIS spacecraft, J. Geophys. Res., 114, A00C12, doi:10.1029/2008JA013488, 2009. 